\title{
Effects of the arbuscular mycorrhizal fungus Glomus mosseae on growth and metal uptake by four plant species in copper mine tailings
}

\author{
B.D. Chen ${ }^{\text {a,* }}$, Y.-G. Zhu ${ }^{\text {a }}$, J. Duan ${ }^{\text {a }}$, X.Y. Xiao ${ }^{\text {a }}$, S.E. Smith ${ }^{b}$ \\ ${ }^{a}$ Department of Soil Environmental Science, Research Center for Eco-environmental Sciences, Chinese Academy of Sciences, \\ Beijing, 100085, PR China \\ ${ }^{\mathrm{b}}$ Centre for Soil-Plant Interactions, School of Earth and Environmental Sciences, Waite Campus, The University of Adelaide, \\ South Australia 5005, Australia
}

Received 10 March 2006; accepted 14 April 2006

This study demonstrated that AM associations can encourage plant survival in Cu mine tailings.

\begin{abstract}
A greenhouse experiment was conducted to evaluate the potential role of arbuscular mycorrhizal fungi (AMF) in encouraging revegetation of copper $(\mathrm{Cu})$ mine tailings. Two native plant species, Coreopsis drummondii and Pteris vittata, together with a turf grass, Lolium perenne and a leguminous plant Trifolium repens associated with and without AMF Glomus mosseae were grown in Cu mine tailings to assess mycorrhizal effects on plant growth, mineral nutrition and metal uptake. Results indicated that symbiotic associations were successfully established between G. mosseae and all plants tested, and mycorrhizal colonization markedly increased plant dry matter yield except for $L$. perenne. The beneficial impacts of mycorrhizal colonization on plant growth could be largely explained by both improved $\mathrm{P}$ nutrition and decreased shoot $\mathrm{Cu}$, As and $\mathrm{Cd}$ concentrations. The experiment provided evidence for the potential use of local plant species in combination with AMF for ecological restoration of metalliferous mine tailings.
\end{abstract}

(C) 2006 Elsevier Ltd. All rights reserved.

Keywords: Copper; Arbuscular mycorrhizal fungi; Mine tailings; Revegetation

\section{Introduction}

Copper $(\mathrm{Cu})$ tailings, produced from extraction and processing of copper ores, not only damage native vegetation, thus leading to large areas of derelict land, but are also sources of metal contaminants in local water, air and land (Freedman, 1995; Wong, 2003). In China, it has been estimated that there are over 8000 national and 230,000 private mining companies that produce around 60 million tonne of mining wastes annually (Young, 1988). These waste piles pose

\footnotetext{
* Corresponding author. Tel.: +8610 62849158; fax: +86 1062923563.

E-mail address: bdchen@rcees.ac.cn (B.D. Chen).
}

huge environmental risks and call for appropriate management. The use of vegetation for landscaping, stabilization and pollution control is probably the most realistic approach to the reclamation of the land impacted by mining wastes (Bradshaw and Johnson, 1992). One of the key factors determining successful revegetation is the initial establishment of plants that can colonize mine tailings progressively. However, vegetation establishment on mine tailings is often difficult, and it was suggested that the major constraints to revegetation in many metal mine tailings are metal toxicity, low nutrient contents and poor physical structures (Ye et al., 2002). In order to promote plant establishment, it is essential to improve the physical and chemical properties of the substrate. 
In addition to the selection of appropriate plant species for revegetation, soil microbes, such as arbuscular mycorrhizal fungi (AMF) are also important to promote plant growth in metal contaminated soils/substrates. The principal role of AMF in assisting plant growth is their capability to supply the host plants with mineral nutrients, particularly phosphate and trace elements (Li et al., 1991; Jakobsen et al., 2002). AMF can also improve soil structure through the actions of external hyphae and glomalin excreted by external hyphae (Rillig and Steinberg, 2002), and maintain plant biodiversity and ecosystem stability (van der Heijden et al., 1998; Koide and Dickie, 2002). Furthermore, under metal contamination, AMF may protect host plants against excessively high metal concentrations in soils (Leyval et al., 2002; Christie et al., 2004). AMF should be an important component in revegetation programs at mining sites, including mine tailings ponds.

In this study, we collected the copper tailings from Tongling City (the city of copper), southern China, and two native plant species, Coreopsis drummondii Torr. et Gray (goldenwave coreopsis) and Pteris vittata L. (Chinese brake fern) were also collected. In addition to a turf grass, Lolium perenne L. (perennial ryegrass) and a leguminous plant Trifolium repens Linn. (white clover), the four plant species associated with and without AMF Glomus mosseae were grown in the $\mathrm{Cu}$ tailings. Mycorrhizal effects on plant growth, mineral nutrition and metal uptake could therefore be assessed. We aimed to reveal the importance of mycorrhizal associations in plant adaptation to multi-stresses in mine tailings, and also the potential use of either local wild or cultivated plant species in association with AMF for revegetation purposes.

\section{Materials and methods}

\subsection{Mine tailings samples}

Copper mine tailings samples were collected from Shangshulin tailings site $\left(\mathrm{N} 30^{\circ} 56.158^{\prime \prime}, \mathrm{E} 117^{\circ} 47.491^{\prime \prime}\right)$ in Tongling City, Anhui Province, China. The tailings had a pH value of 8.68 (1:2.5 tailings to water), $1.63 \%$ organic matter, $0.031 \%$ total $\mathrm{N}$. Total $\mathrm{N}$ content and organic matter were determined by the Kjeldahl method (Kjeldahl, 1883) and modified Tiurin's method (Mebius, 1960) respectively. The tailings were in short supply of available $\mathrm{P}$ with a content of $1.56 \mathrm{mg} \mathrm{kg}^{-1}$ that extracted by $0.5 \mathrm{~mol} \mathrm{~L}^{-1} \mathrm{NaHCO}_{3}$, and determined colorimetrically by the vanadomolybdate method following the methods described by Olsen et al. (1954) and Murphy and Riley (1962). The tailings contained $232 \mathrm{mg} \mathrm{Cu} \mathrm{kg}, 81 \mathrm{mg} \mathrm{Pb} \mathrm{kg}^{-1}, 54 \mathrm{mg} \mathrm{As} \mathrm{kg}^{-1}, 2.5 \mathrm{mg} \mathrm{Cd} \mathrm{kg}^{-1}$ and $189 \mathrm{mg} \mathrm{Zn} \mathrm{kg}^{-1}$. Total metal concentrations were measured by inductively coupled plasma-optical emission spectroscopy (ICP-OES) using a Perkin Elmer Optima $2000 \mathrm{DV}$ following $\mathrm{HNO}_{3}-\mathrm{HClO}_{4}$ digestion. Before the experiment, the samples were passed through a $2 \mathrm{~mm}$ sieve, autoclaved $\left(121{ }^{\circ} \mathrm{C}, 2 \mathrm{~h}\right)$ and amended with basal nutrients (Pearson and Jakobsen, 1993).

\subsection{Mycorrhizal fungus}

The AM fungus used was Glomus mosseae (Nicol. \& Gerd.) Gerdemann \& Trappe (BEG167). The fungus was propagated on maize plants (Zea mays L.) grown in a sandy soil for 10 weeks. The soil had the following properties (DM basis): $\mathrm{pH}$ (soil:water ratio, $1: 2.5) 7.8,0.39 \%$ organic matter, $0.027 \%$ total $\mathrm{N}$, $3.9 \mathrm{mg} \mathrm{kg}^{-1} 0.5 \mathrm{M} \mathrm{NaHCO}_{3}$-extractable P. Inoculum comprised of the sandy soil containing fungal spores, mycelium, and root fragments.

\subsection{Plants}

Spores of $P$. vittata were collected from Fenghuangshan, Tongling City, Anhui Province, China. Yong plants were raised from spores in sterilized growth medium (sandy soil and vermiculite with a mixing ratio of $2: 1 \mathrm{v} / \mathrm{v}$ ) in $2-\mathrm{L}$ round plastic pots. When the young plants had two fronds and were about $3 \mathrm{~cm}$ in height, they were used for establishment of the experiment.

Seeds of $C$. drummondii were collected from Yangshulin tailings, Tongling City. Seeds of $T$ repens and $L$. perenne were purchased from Chinese Academy of Agricultural Sciences. Seeds of these three plant species were pre-germinated on moist filter paper for about $48 \mathrm{~h}$ until the radicles appeared. They were selected for uniformity before sowing.

\subsection{Pot experiment}

Each individual plant of the four species received $60 \mathrm{~g}$ inoculum of $G$. mosseae for inoculation treatments, or equivalent sterilized inoculum for non-inoculated controls, which resulted in 8 treatments. There were 4 replicates for each treatment and totally 32 pots in a randomized block design. The amended growth medium was put into cylindrical plastic pots (diameter $10 \mathrm{~cm} \times 10 \mathrm{~cm}$ ) at $940 \mathrm{~g} \mathrm{pot}^{-1}$. Two young plants of $P$. vittata were transplanted. Four seeds of $C$. drummondii, 15 seeds of $L$. perenne, and approximately 30 seeds of $T$. repens were sown in each pot, depending on treatments. Seven days after emergence, seedlings were thinned to 2 for $C$. drummondii, 7 for $L$. perenne and 10 for $T$. repens for further growth. The experiment was conducted in a controlled greenhouse with $16 \mathrm{~h} 25^{\circ} \mathrm{C}$ day and $8 \mathrm{~h} 18{ }^{\circ} \mathrm{C}$ night and natural light. The plants grew for 3 months from 8 September to 9 December 2003. De-ionized water was added as required to maintain moisture content at $55 \%$ of water holding capacity by regular weighing. Nitrogen $\left(\right.$ as $\left.\mathrm{NH}_{4} \mathrm{NO}_{3}\right)$ was added to the pots at days 30 and 60 after sowing to provide a total of $120 \mathrm{mg} \mathrm{N}$ per pot.

\subsection{Harvest and chemical analysis}

Plant shoots and roots were harvested separately. Root samples were carefully washed with tap water and then deionised water to remove adhering soil particles. Sub-samples of fresh roots were collected for the determination of AM colonization rate. The dry weights of shoots and roots were determined after oven drying at $70{ }^{\circ} \mathrm{C}$ for $48 \mathrm{~h}$. Oven-dried sub-samples were milled and digested by $5 \mathrm{ml} \mathrm{HNO}$ at $160{ }^{\circ} \mathrm{C}$ using the microwave accelerated reduction system (Mars 5, CEM Co. Ltd, USA). The dissolved samples were analyzed for $\mathrm{P}, \mathrm{Cu}$ and $\mathrm{Zn}$ using ICP-AES. Arsenic (As) concentrations were determined using an atomic fluorescence spectrometer (Model AF-610A, Beijing Rayleigh Analytical Instrument Co., China), and Cd by inductively coupled plasma-mass spectroscopy (ICP-MS) (Finnigan Mat, Germany).

Sub-samples of fresh roots were cleared in $10 \% \mathrm{KOH}$ and stained with Trypan blue by a modification procedure of Phillips and Hayman (1970), omitting phenol from solutions and $\mathrm{HCl}$ from the rinse. Percentage root colonization and root length were determined by the grid-intersect method (Giovanetti and Mosse, 1980).

\subsection{Data analysis}

All data were subjected to one-way analysis of variance (ANOVA) to compare mycorrhizal status using Windows-based Genstat (Payne, 2002).

\section{Results}

\subsection{Plant growth and mycorrhizal colonization}

Mycorrhizal colonization increased both shoot and root biomass significantly for all the tested plant species, except L. perenne. $P$. vittata had the greatest growth response to mycorrhizal colonization followed by $T$. repens (Fig. 1). Mycorrhizal 
(A)

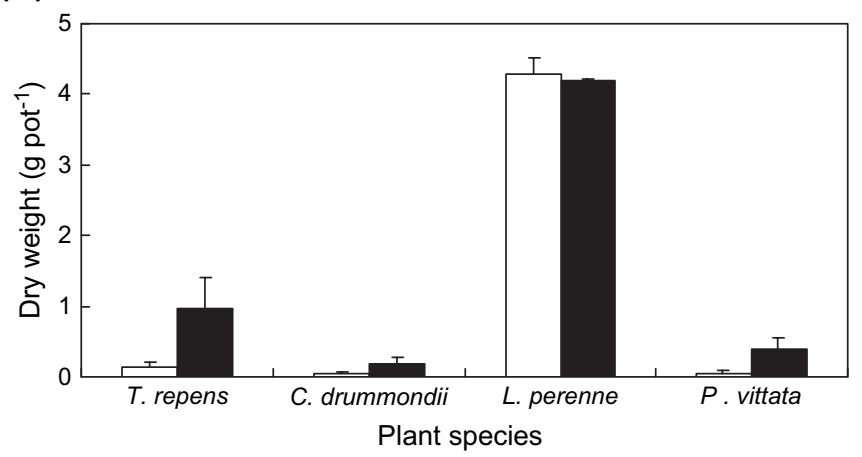

(B)

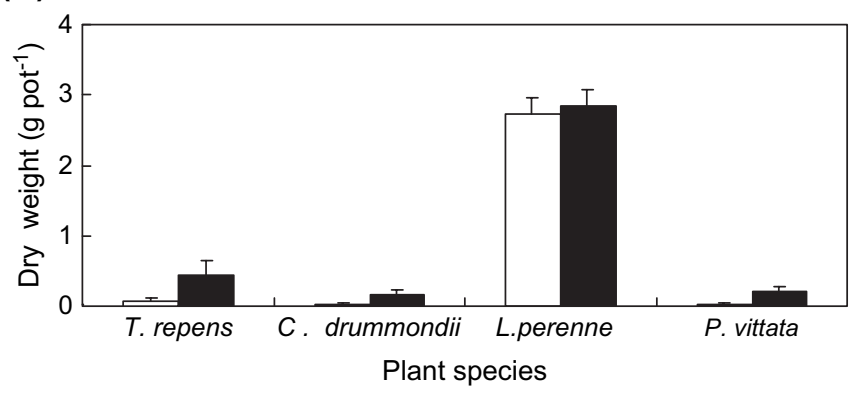

Fig. 1. Shoot (A) and root (B) dry weights of different plant species in association with AMF G. mosseae on copper mine tailings. Open bars, non-inoculated controls; solid bars, inoculated with G. mosseae. By analysis of variance, inoculation was significant $(P<0.05)$ for both shoot and root of $T$. repens and $C$. drummondii, highly significant $(P<0.01)$ for those of $P$. vittata, but not significant for L. perenne.

colonization also increased significantly the root length of $P$. vittata, T. repens and $C$. drummondii $(P<0.001)$, but not $L$. perenne (Table 1). However, percentages of root length of all plants colonized by $G$. mosseae were not high in this experiment ranging from 3 to $24 \%$ (Table 1).

\subsection{Phosphorus $(P)$ uptake}

Mycorrhizal colonization significantly increased P concentrations in both roots and shoots of $C$. drummondii and shoots of $T$. repens, but only had a marginal effect on the other plant species (Fig. 2). Due to the significant increase in plant biomass with mycorrhizal colonization, mycorrhizal colonization substantially increased total $\mathrm{P}$ contents in all plants except $L$. perenne (Table 2).
(A)

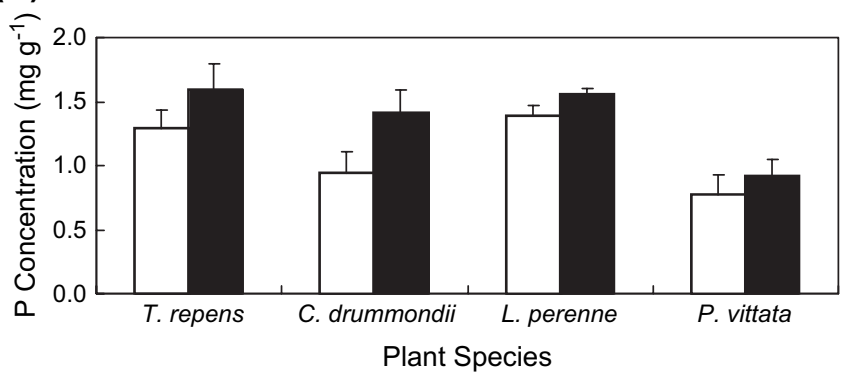

(B)

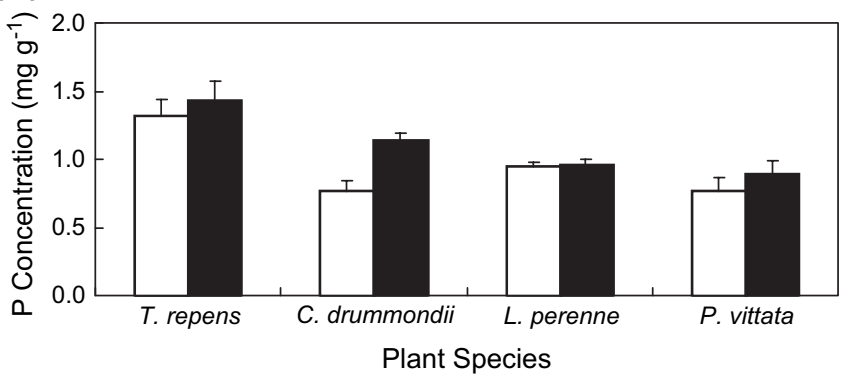

Fig. 2. Shoot (A) and root (B) $\mathrm{P}$ concentrations in different plant species in association with AMF G. mosseae on copper mine tailings. Open bars, non-inoculated controls; solid bars, inoculated with G. mosseae. By analysis of variance, inoculation was highly significant $(P<0.01)$ for both shoot and root of coreopsis, significant $(P<0.05)$ for shoot of $L$. perenne.

\subsection{Plant uptake of metals}

For $P$. vittata, $T$. repens and $C$. drummondii, AMF significantly reduced $\mathrm{Cu}$ concentrations in shoots, however, $\mathrm{Cu}$ concentrations in shoots showed little difference between plant species when colonized by AMF (Fig. 3). AMF colonization had no effect on $\mathrm{Cu}$ concentrations in shoots of L perenne. Without AMF colonization, $\mathrm{Cu}$ concentrations in shoots of $P$. vittata and $C$. drummondii were much higher than in shoots of $T$. repens and $L$. perenne. AMF had a marginal effect on $\mathrm{Cu}$ concentrations in roots of all tested plants, but large inter-specific differences were observed with $P$. vittata having the highest root $\mathrm{Cu}$ concentrations (up to $800 \mathrm{mg} \mathrm{kg}^{-1}$ ). Except for $T$. repens, root to shoot ratios of total $\mathrm{Cu}$ uptake of the other plants were markedly increased by mycorrhizal colonization (Table 3).

AMF colonization did not affect $\mathrm{Zn}$ concentrations in shoots of $T$. repens and $C$. drummondii, but reduced those in shoots of $P$. vittata and increased those in shoots of $L$. perenne

Table 1

Total root length and percentage root colonized of different plants in association with AMF G. mosseae on copper mine tailings

\begin{tabular}{|c|c|c|c|c|}
\hline \multirow[t]{2}{*}{ Plant species } & \multicolumn{2}{|c|}{ Root Length (m pot ${ }^{-1}$ ) } & \multicolumn{2}{|c|}{ Percentage root colonized (\%) } \\
\hline & $-\mathrm{M}$ & $+\mathrm{M}$ & $-\mathrm{M}$ & $+\mathrm{M}$ \\
\hline T. repens & $7.30 \pm 2.91$ & $63.50 \pm 31.72$ & $0.0 \pm 0.0$ & $24.2 \pm 3.8$ \\
\hline L. perenne & $400.88 \pm 142.12$ & $525.16 \pm 48.42$ & $0.0 \pm 0.0$ & $3.2 \pm 1.1$ \\
\hline P. vittata & $1.39 \pm 0.49$ & $7.49 \pm 1.87$ & $0.0 \pm 0.0$ & $18.0 \pm 4.4$ \\
\hline
\end{tabular}

Data were presented as mean \pm standard error $(n=4)$. 
Table 2

Plant $\mathrm{P}$ content of different plant species in association with AMF G. mosseae on copper mine tailings

\begin{tabular}{llllll}
\hline Plant species & \multicolumn{2}{l}{ Shoot $\mathrm{P}$ content $\left(\mathrm{mg} \mathrm{pot}^{-1}\right)$} & & \multicolumn{2}{l}{ Root P content $\left(\mathrm{mg} \mathrm{pot}^{-1}\right)$} \\
\cline { 2 - 3 } \cline { 5 - 6 } & $-\mathrm{M}$ & $+\mathrm{M}$ & & $-\mathrm{M}$ & $+\mathrm{M}$ \\
\hline T. repens & $0.20 \pm 0.10$ & $1.56 \pm 0.79$ & & $0.10 \pm 0.06$ & $0.63 \pm 0.29$ \\
C. drummondii & $0.04 \pm 0.01$ & $0.26 \pm 0.16$ & & $0.03 \pm 0.02$ & $0.20 \pm 0.09$ \\
L. perenne & $5.96 \pm 0.30$ & $6.50 \pm 0.18$ & & $2.58 \pm 0.25$ & $2.73 \pm 0.34$ \\
P. vittata & $0.05 \pm 0.04$ & $0.37 \pm 0.19$ & & $0.02 \pm 0.01$ & $0.18 \pm 0.08$ \\
\hline
\end{tabular}

Data were presented as mean \pm standard error $(n=4)$.

(Fig. 4). AMF had marginal effects on Zn concentrations in the roots of all tested plant species. Mycorrhizal colonization decreased root to shoot ratio of total $\mathrm{Zn}$ uptake for rye grass $(P<0.05)$, but had no significant influences on $\mathrm{Zn}$ partitioning in the other plant species (Table 3).

AMF colonization significantly reduced shoot As concentrations all plants in except L. perenne (Fig. 5), and As concentrations in $P$. vittata were the highest among the four plant species (17.8 and $27.0 \mathrm{mg} \mathrm{kg}^{-1}$ with or without AMF, respectively). AMF did not significantly affect As concentrations in roots except those in $T$. repens roots which were decreased by AMF colonization. Mycorrhizal colonization increased only root to shoot ratio of total As uptake for $C$. drummondii $(P<0.01)$ (Table 3).

AMF colonization substantially reduced $\mathrm{Cd}$ concentrations in shoots of $T$. repens, $C$. drummondii and $P$. vittata, but did not affect those of L. perenne (Fig. 6). AMF did not affect
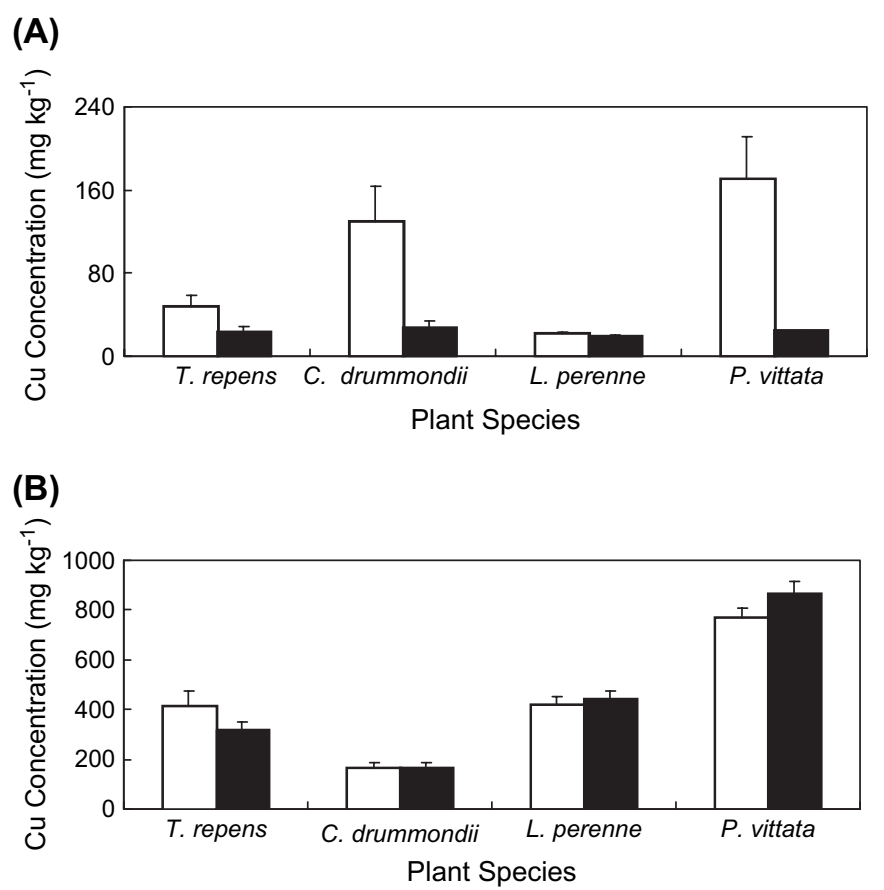

Fig. 3. Shoot (A) and root (B) Cu concentrations in different plant species in association with AMF G. mosseae on copper mine tailings. Open bars, non-inoculated controls; solid bars, inoculated with $G$. mosseae. By analysis of variance, inoculation was significant $(P<0.05)$ for both shoot and root of $T$. repens and $C$. drummondii, highly significant $(P<0.01)$ for those of $P$. vittata, but not significant for $L$. perenne.
Cd concentrations in roots except that in $P$. vittata. Except for $L$. perenne, root to shoot ratios of total $\mathrm{Cd}$ uptake by the other plants were significantly increased by mycorrhizal colonization (Table 3).

\section{Discussion}

$P$. vittata and $C$. drummondii naturally colonize $\mathrm{Cu}$ mine tailings in Tongling, southern China, and they are highly mycorrhizal under field conditions (Chen et al., 2005). Results from the present study demonstrated that both plant species were highly dependent on mycorrhizal colonization for growth when grown in $\mathrm{Cu}$ mine tailings. Their mycorrhizal responsiveness (in terms of growth improvement) was similar to that of $T$. repens, which is known to be highly dependent on mycorrhizal colonization (Zhu et al., 2001). However, in terms of tissue $\mathrm{P}$ concentrations, AMF colonization only marginally increased tissue $\mathrm{P}$ concentrations (Fig. 2), which is probably due to the growth dilution effect, since AMF increased plant biomass by almost 6 times for $P$. vittata, $T$. repens and $C$. drummondii (Fig. 1). Results from the present study highlighted the importance of AMF in accelerating plant growth in $\mathrm{Cu}$ mine tailings.

At heavy metal contaminated sites, there is usually a short supply of necessary mineral nutrients in combination with excessive metals (Shetty et al., 1994; Chen et al., 2005). With the help of arbuscular mycorrhiza, a host plant can obtain more nutrients and plant resistance to metal contamination can be enhanced. Therefore, for soil remediation purposes, it is possible to use arbuscular mycorrhizas for revegetation of mining sites or barren land, or restoration of disturbed ecosystems. Furthermore, on moderately or slightly contaminated agricultural land, mycorrhizal associations could be used to protect crops from metal contamination and maintain soil productivity. Even when AM fungi are not applied to the soil, a good strategy may be necessary to ensure that field conditions are favourable for the development of mycorrhizal associations involving indigenous AM fungi. Considering the foreseeable exhaustion of phosphorus minerals within decades, AM fungi as biological resources can be conserved and exploited to facilitate plant $\mathrm{P}$ acquisition under short $\mathrm{P}$ supply.

There are over 450 plant species that have been identified as hyperaccumulators of various metals, such $\mathrm{Zn}, \mathrm{Ni}$ and $\mathrm{Cd}$ (Brooks et al., 1998). However, most of these hyperaccumulators belong to the family of Cruciferae, and are non-mycorrhizal, thus in contrast to the ubiquity of AMF in terrestrial ecosystems, there is limited information available regarding the influence of AMF on phytoremediation (Khan et al., 2000). P. vittata is highly mycorrhizal both under field and pot experimental conditions (Chen et al., 2005; Liu et al., 2005). It provides an opportunity to investigate the effects of AMF on the accumulation of metals by hyperaccumulators. The current experiment revealed that AMF reduced As concentrations in above-ground parts of $P$. vittata, but As concentrations in roots were similar between mycorrhizal and non-mycorrhizal plants. Therefore, the reduction in As concentrations in aboveground may be also resulted from a "dilution effect" due to the substantial 
Table 3

Metal uptake $\left(\mu \mathrm{g} \mathrm{pot}^{-1}\right)$ of and partitioning in different plant species in association with AMF G. mosseae on copper mine tailings

\begin{tabular}{|c|c|c|c|c|c|c|c|c|}
\hline \multirow[t]{2}{*}{ Plant species } & \multicolumn{2}{|l|}{$\mathrm{Cu}$} & \multicolumn{2}{|l|}{$\mathrm{Zn}$} & \multicolumn{2}{|l|}{ As } & \multicolumn{2}{|l|}{$\mathrm{Cd}$} \\
\hline & $-\mathrm{M}$ & $+\mathrm{M}$ & $-\mathrm{M}$ & $+\mathrm{M}$ & $-\mathrm{M}$ & $+\mathrm{M}$ & $-\mathrm{M}$ & $+\mathrm{M}$ \\
\hline \multicolumn{9}{|l|}{ Shoot } \\
\hline T. repens & $6.79 \pm 2.95$ & $19.92 \pm 5.44$ & $5.81 \pm 3.16$ & $37.01 \pm 16.61$ & $0.25 \pm 0.11$ & $0.81 \pm 0.59$ & $0.10 \pm 0.04$ & $0.13 \pm 0.03$ \\
\hline C. drummondii & $5.35 \pm 4.06$ & $4.70 \pm 1.78$ & $2.32 \pm 1.27$ & $10.48 \pm 5.91$ & $0.25 \pm 0.09$ & $0.36 \pm 0.10$ & $0.08 \pm 0.02$ & $0.23 \pm 0.12$ \\
\hline L. perenne & $92.07 \pm 5.61$ & $81.01 \pm 4.51$ & $173.67 \pm 10.82$ & $216.90 \pm 18.81$ & $3.49 \pm 0.27$ & $4.13 \pm 0.44$ & $0.86 \pm 0.10$ & $0.71 \pm 0.04$ \\
\hline$P$. vittata & $7.59 \pm 5.45$ & $9.50 \pm 3.71$ & $1.59 \pm 1.28$ & $5.45 \pm 2.23$ & $1.34 \pm 1.09$ & $6.80 \pm 2.03$ & $0.06 \pm 0.07$ & $0.07 \pm 0.02$ \\
\hline \multicolumn{9}{|l|}{ Root } \\
\hline T. repens & $31.23 \pm 18.16$ & $143.25 \pm 76.51$ & $7.20 \pm 5.15$ & $28.97 \pm 12.22$ & $0.57 \pm 0.35$ & $1.58 \pm 0.91$ & $0.35 \pm 0.29$ & $1.75 \pm 0.79$ \\
\hline C. drummondii & $5.88 \pm 4.57$ & $28.65 \pm 15.53$ & $0.86 \pm 0.57$ & $4.11 \pm 2.03$ & $0.25 \pm 0.11$ & $0.90 \pm 0.20$ & $0.04 \pm 0.02$ & $0.20 \pm 0.15$ \\
\hline L. perenne & $1129.22 \pm 97.76$ & $1267.34 \pm 176.60$ & $159.57 \pm 26.35$ & $144.14 \pm 19.92$ & $13.45 \pm 2.80$ & $15.92 \pm 6.09$ & $10.48 \pm 1.45$ & $10.10 \pm 2.82$ \\
\hline$P$. vittata & $21.32 \pm 12.09$ & $173.26 \pm 73.01$ & $2.14 \pm 1.08$ & $14.07 \pm 6.45$ & $0.44 \pm 0.19$ & $3.11 \pm 1.06$ & $0.11 \pm 0.05$ & $1.45 \pm 0.79$ \\
\hline \multicolumn{9}{|c|}{ Root to shoot ratio of total metal uptake } \\
\hline T. repens & $4.86 \pm 2.04$ & $6.83 \pm 1.77$ & $1.30 \pm 0.47$ & $0.80 \pm 0.07$ & $2.43 \pm 1.32$ & $2.09 \pm 0.47$ & $3.57 \pm 2.93$ & $13.68 \pm 5.96$ \\
\hline C. drummondii & $1.09 \pm 0.04$ & $5.97 \pm 1.44$ & $0.38 \pm 0.11$ & $0.40 \pm 0.05$ & $1.03 \pm 0.40$ & $2.70 \pm 0.68$ & $0.37 \pm 0.04$ & $0.87 \pm 0.28$ \\
\hline L. perenne & $12.27 \pm 0.93$ & $15.65 \pm 2.07$ & $0.92 \pm 0.12$ & $0.67 \pm 0.12$ & $3.88 \pm 0.84$ & $3.82 \pm 1.20$ & $12.26 \pm 1.43$ & $14.26 \pm 3.66$ \\
\hline P. vittata & $3.18 \pm 0.71$ & $18.28 \pm 2.04$ & $1.79 \pm 0.91$ & $2.63 \pm 0.66$ & $0.49 \pm 0.27$ & $0.45 \pm 0.05$ & $3.06 \pm 3.01$ & $18.68 \pm 5.42$ \\
\hline
\end{tabular}

Data were presented as mean \pm standard error $(n=4)$.

growth gain with AMF. "Dilution effect" has been proposed as a possible mechanism how AMF improve the tolerance to metal toxicity of host plants (Leyval et al., 1997). In this context, mycorrhizal roots may act as bio-filtration system.

The effects of AMF on plant uptake of heavy metals, such as $\mathrm{Zn}$ and $\mathrm{Cd}$ have been studied extensively in recent years (Joner and Leyval, 1997; Zhu et al., 2001; Chen et al.,

\section{(A)}

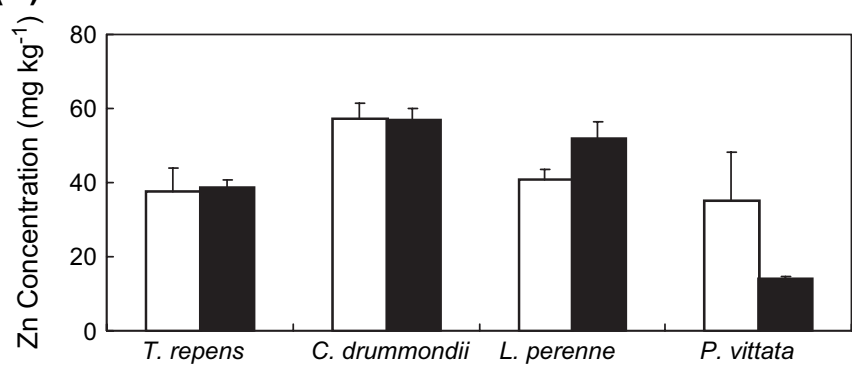

Plant Species

(B)

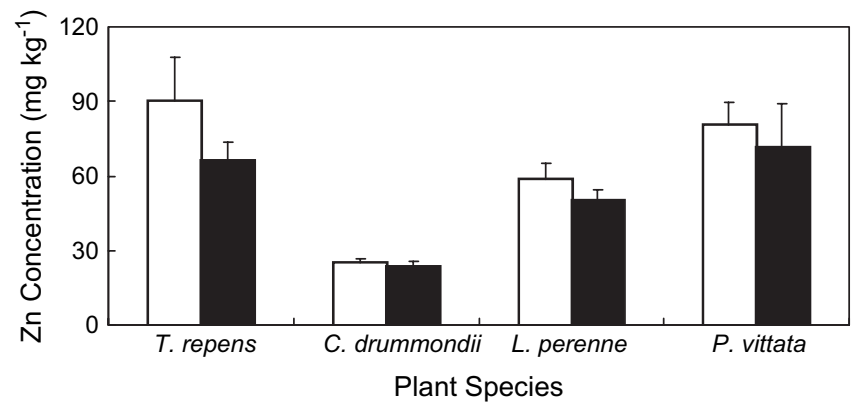

Fig. 4. Shoot (A) and root (B) $\mathrm{Zn}$ concentrations in different plant species in association with AMF G. mosseae on copper mine tailings. Open bars, non-inoculated controls; solid bars, inoculated with $G$. mosseae. By analysis of variance, inoculation was highly significant $(P<0.01)$ for shoot of $T$. repens, $C$. drummondii and $P$. vittata, significant $(P<0.05)$ for shoot of $L$. perenne, root of $T$. repens and $P$. vittata.
2003), and it is generally accepted that under high metal concentrations in the soil, AMF may protect the host plants against metal toxicity (Leyval et al., 2002). The protection may largely be mediated by metal sequestration by

(A)

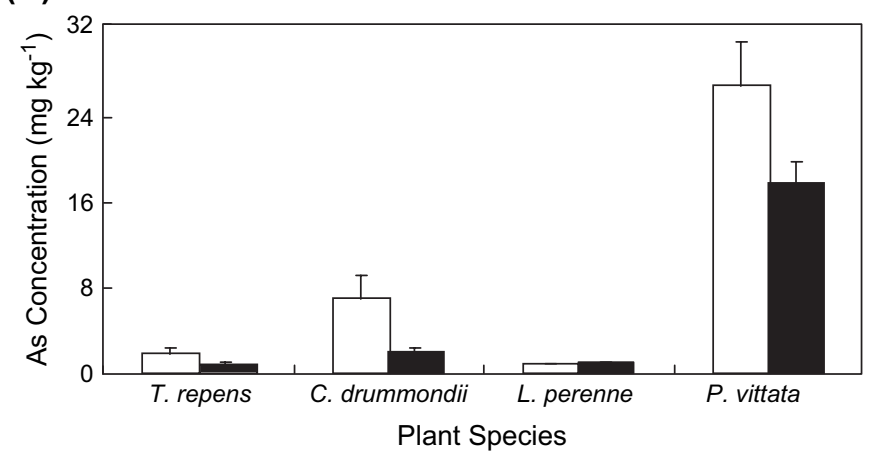

(B)

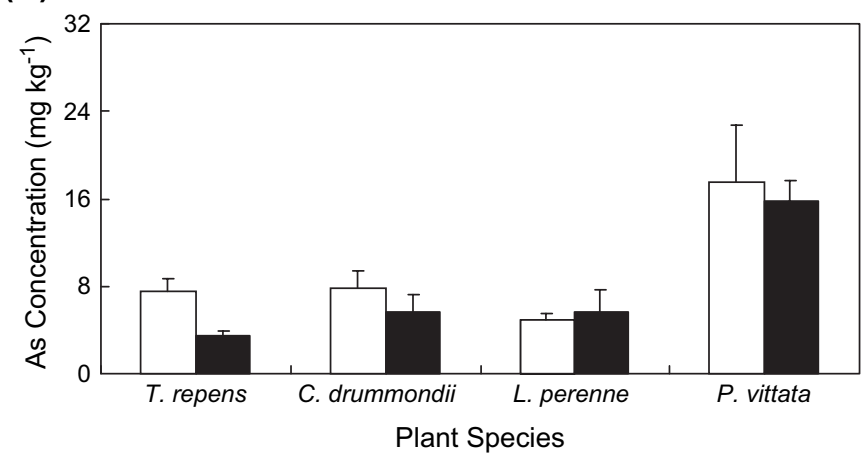

Fig. 5. Shoot (A) and root (B) As concentrations in different plant species in association with AMF G. mosseae on copper mine tailings. Open bars, non-inoculated controls; solid bars, inoculated with $G$. mosseae. By analysis of variance, inoculation was significant $(P<0.05)$ for shoot, and highly significant $(P<0.01)$ for root of $T$. repens. Shoot As concentrations in $C$. drummondii and $P$. vittata were also highly significantly $(P<0.01)$ influenced by mycorrhizal inoculation. 
(A)

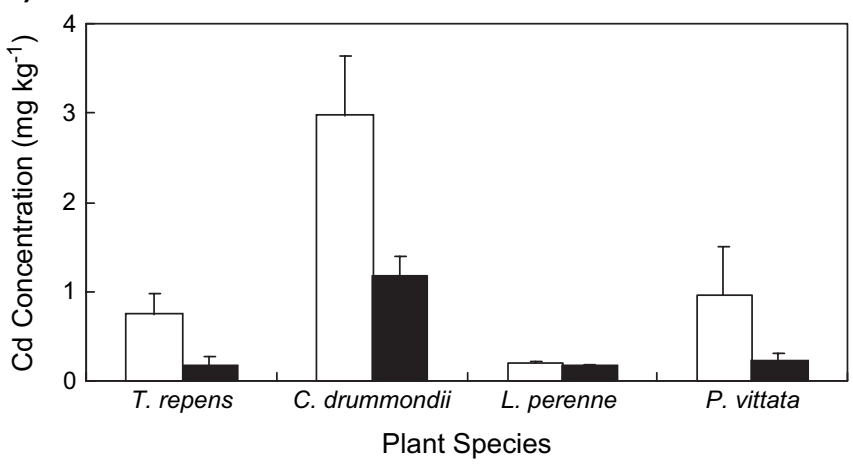

(B)

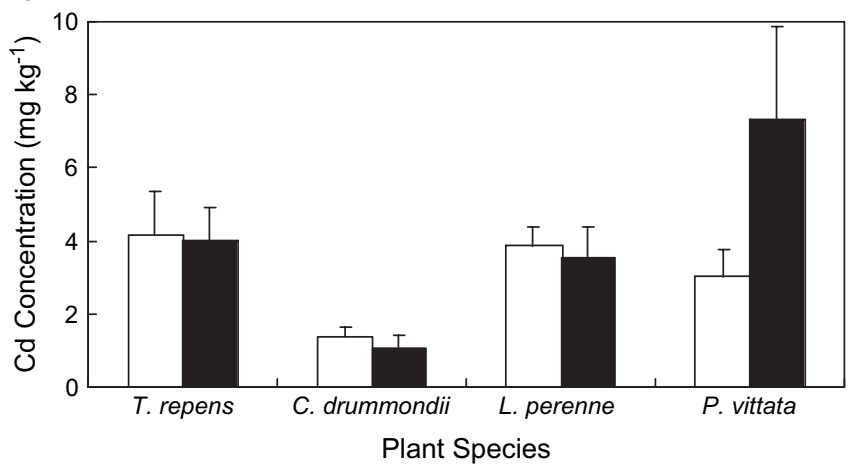

Fig. 6. Shoot (A) and root (B) Cd concentrations in different plant species in association with AMF G. mosseae on copper mine tailings. Open bars, non-inoculated controls; solid bars, inoculated with G. mosseae. By analysis of variance, inoculation was highly significant $(P<0.01)$ for shoot of $T$. repens, and significant $(P<0.05)$ for other three plant species. Inoculation only showed significant $(P<0.05)$ influences on root Cd concentration of $P$. vittata.

mycorrhizal structures, and it has been demonstrated that $\mathrm{Cd}$ and $\mathrm{Zn}$ could be strongly bound by mycorrhizal hyphae both in vivo (Chen et al., 2001) and in vitro (Joner et al., 2000). The growth substrate used in the present study contained toxic levels of $\mathrm{Cu}$ and $\mathrm{Cd}$ as well as As. Results obtained clearly showed that AMF significantly reduced the concentrations of $\mathrm{Cu}$ and $\mathrm{Cd}$ in aboveground tissues of $P$. vittata, $C$. drummondii and T. repens. Similar to As, the key mechanism of AMF-mediated reduction in $\mathrm{Cu}$ and $\mathrm{Cd}$ concentrations in aboveground parts is a "dilution effect". In the case of $\mathrm{Cd}$ accumulation by $P$. vittata, the "dilution effect" was even stronger, since AMF significantly increased $\mathrm{Cd}$ concentrations in roots, but $\mathrm{Cd}$ concentrations in aboveground parts were again reduced substantially, indicating that the $\mathrm{Cd}$ may be even more strongly bound in the mycorrhizal roots.

This work has clearly demonstrated that AM associations could encourage plant survival and improve plant growth by facilitating mineral nutrition in $\mathrm{Cu}$ mine tailings. More importantly, delicate plant species that are sensitive to stresses such as nutrient deficiency and metal toxicity can benefit much from symbiotic partners and successfully colonize degraded land, which can consequently enrich plant biodiversity and stabilize the ecosystems. Recently, the importance of conservation of underground biodiversity has been recruited and received much research interest (Pennisi, 2004; Wardle et al., 2004). The potential role of AM fungi in maintenance of plant diversity at mine tailings sites further revealed the functional importance of these microorganisms in fragile ecosystems. There is no doubt that there is an urgent need to conduct further investigations to understand the involvement of AMF in plant interactions and encouraging biodiversity at mine tailings sites and to reveal the underlying mechanisms.

\section{Acknowledgements}

This study was supported by the Natural Science Foundation of China (40401031) and the Ministry of Science and Technology of China (Project No. 2001AA645010-4 and 2002CB410808).

\section{References}

Bradshaw, A.D., Johnson, M., 1992. Revegetation of Metalliferous Mine Wastes: The Range of Practical Techniques Used in Western Europe. Elsevier, Manchester.

Brooks, R.R., Chambers, M.F., Nicks, L.J., Robinson, B.H., 1998. Phytomining. Trends in Plant Science 3 (9), 359-362.

Chen, B.D., Christie, P., Li, X.L., 2001. A modified glass bead compartment cultivation system for the study of nutrient uptake by arbuscular mycorrhizae. Chemosphere 42, 185-192.

Chen, B.D., Li, X.L., Tao, H.Q., Christie, P., Wong, M.H., 2003. The role of arbuscular mycorrhiza in zinc uptake by red $T$. repens growing in a calcareous soil spiked with various quantities of zinc. Chemosphere 50, 839-846.

Chen, B.D., Tang, X.Y., Zhu, Y.-G., Christie, P., 2005. Metal concentrations and mycorrhizal status of plants colonizing copper mine tailings: potential for revegetation. Science in China (Ser. C) 48 (Supp. I), 156-164.

Christie, P., Li, X.L., Chen, B.D., 2004. Arbuscular mycorrhiza can depress translocation of zinc to shoots of host plants in soils moderately polluted with zinc. Plant and Soil 261, 209-217.

Freedman, B., 1995. Environmental Ecology - The Ecological Effects of Pollution Disturbance and Other Stresses. Academic Press, London.

Giovanetti, M., Mosse, B., 1980. An evaluation of techniques for measuring vesicular arbuscular mycorrhizal infection in roots. New Phytologist 84, 489-500

Jakobsen, I., Smith, S.E., Smith, F.A., 2002. Function and diversity of arbuscular mycorrhizae in carbon and mineral nutrition. In: van der Heijden, M.G.A., Sanders, I.R. (Eds.), Mycorrhizal Ecology. Springer-Verlag, Berlin, pp. 75-92.

Joner, E.J., Briones, R., Leyval, C., 2000. Metal-binding capacity of arbuscular mycorrhizal mycelium. Plant and Soil 226, 227-234.

Joner, E.J., Leyval, C., 1997. Uptake of ${ }^{109} \mathrm{Cd}$ by roots and hyphae of a Glomus mosseae/Trifolium subterraneum mycorrhiza from soil amended with high and low concentrations of cadmium. New Phytologist 135, 353-360.

Khan, A.G., Kuek, C., Chaudhry, T.M., Khoo, C.S., Hayes, W.J., 2000. Role of plants, mycorrhizae and phytochelators in heavy metal contaminated land remediation. Chemosphere 41, 197-207.

Kjeldahl, J., 1883. A new method for the determination of nitrogen in organic matter. Zeitschrift fur Analytische Chemie Fresenius 22, 366-382.

Koide, R.T., Dickie, I.A., 2002. Effects of mycorrhizal fungi on plant populations. Plant and Soil 244, 307-317.

Leyval, C., Joner, E.J., del Val, C., Haselwandter, K., 2002. Potential of arbuscular mycorrhizal fungi for bioremediation. In: Gianinazzi, S., Schüepp, H., Barea, J.M., Haselwandter, K. (Eds.), Mycorrhizal Technology in Agriculture. Birkhäuser Verlag, Basel, Switzerland, pp. 175-186.

Leyval, C., Turnau, K., Haselwandter, K., 1997. Effect of heavy metal pollution on mycorrhizal colonization and function: physiological, ecological and applied aspects. Mycorrhiza 7, 139-153. 
380

B.D. Chen et al. / Environmental Pollution 147 (2007) 374-380

Li, X.L., Marschner, H., George, E., 1991. Acquisition of phosphorus and copper by VA mycorrhizal hyphae and root-to-shoot transport in white clover. Plant and Soil 136, 49-57.

Liu, Y., Zhu, Y.-G., Chen, B.D., Christie, P., Li, X.L., 2005. Influence of the arbuscular mycorrhizal fungus Glomus mosseae on uptake of arsenate by the As hyperaccumulator fern Pteris vittata L. Mycorrhiza 15, 187-192.

Mebius, L.J., 1960. A rapid method for the determination of organic carbon in soil. Analytica Chimica Acta 22, 120-124.

Murphy, J., Riley, J.P., 1962. A modified single solution method for the determination of phosphate in natural waters. Analytica Chimica Acta 27, 31.

Olsen, S.R., Cole, C.V., Watanabe, F.S., Dean, L.A., 1954. Estimation of Available Phosphorus in Soils by Extraction with Sodium Bicarbonate. USDA Circular No. 939.

Payne, R.W. (Ed.), 2002. The Guide to GenStat Release 6.1 - Part 1: Syntax and Data Management. GenStat Committee, VSN International, Hemel Hempstead, UK.

Pearson, J.N., Jakobsen, I., 1993. The relative contribution of hyphae and roots to phosphorus uptake by arbuscular mycorrhizal plants measured by dual labelling with ${ }^{32} \mathrm{P}$ and ${ }^{33} \mathrm{P}$. New Phytologist $124,489-494$.

Pennisi, E., 2004. The secret life of fungi. Science 304, 1620-1622.

Phillips, J.M., Hayman, D.S., 1970. Improved procedures for clearing and staining parasitic and vesicular-arbuscular mycorrhizal fungi for rapid assessment of infection. Transactions of the British Mycological Society 55, 158-161.
Rillig, M.C., Steinberg, P.D., 2002. Glomalin production by an arbuscular mycorrhizal fungus: a mechanism of habitat modification? Soil Biology and Biochemistry 34, 1371-1374.

Shetty, K.G., Banks, M.K., Hetrick, B.A.D., Schwab, A.P., 1994. Biological characterization of a southeast Kansas mining site. Water, Air and Soil Pollution 78, 169-177.

van der Heijden, M.G.A., Klironomos, J.N., Ursic, M., Moutoglis, P., Streitwolf-Engel, R., Boller, T., Wiemken, A., Sanders, I.R., 1998. Mycorrhizal fungal diversity determines plant biodiversity, ecosystem variability and productivity. Nature 396, 69-72.

Wardle, D.A., Bardgett, R.D., Klironomos, J.N., Setälä, H., van der Putten, W.H., Wall, D.H., 2004. Ecological linkages between aboveground and belowground biota. Science 304, 1629-1633.

Wong, M.H., 2003. Ecological restoration of mine degraded soils, with emphasis on metal contaminated soils. Chemosphere 50, 775-780.

Ye, Z.H., Shu, W.S., Zhang, Z.Q., Lan, C.Y., Wong, M.H., 2002. Evaluation of major constraints to revegetation of lead/zinc mine tailings using bioassay techniques. Chemosphere 47, 1103-1111.

Young, K., 1988. Destruction of ecological habitats by mining activities. Agricultural Ecology 16, 37-40.

Zhu, Y.-G., Christie, P., Laidlaw, A.S., 2001. Uptake of Zn by arbuscular mycorrhizal white clover from Zn-contaminated soil. Chemosphere 42, 193-199. 